\title{
How can transition to adult care be best orchestrated for adolescents with epilepsy?
}

Camfield $P R^{1}$, Andrade $\mathrm{D}^{2}$, Camfield $\mathrm{CS}^{1}$, Carrizosa-Moog $\mathrm{J}^{3}$, Appleton $\mathrm{R}^{4}$, Baulac $\mathrm{M}^{5}$, Brown $L^{6}$, Ben Menachem $E^{7}$, Cross $H^{8}$, Grant $C^{9}$, Hosny $H^{10}$, Jurasek $L^{11}$, Mula $M^{12}$, Pfäfflin $\mathrm{M}^{13}$, Rheims $\mathrm{S}^{14}$, Ring $\mathrm{H}^{15}$, Shellhaas $R A^{16}$, Vinayan $K \mathrm{P}^{17}$, Wirrell $\mathrm{E}^{18}$ and Nabbout $\mathrm{R}^{19}$.

${ }^{1}$ Department of Pediatrics, Dalhousie University, Halifax, Nova Scotia, Canada

${ }^{2}$ Krembil Neurosciences Epilepsy Genetics Program, Division of Neurology, Department of Medicine, Toronto Western Hospital, University of Toronto. Toronto, Canada

${ }^{3}$ Pediatric Department - Adolescent Service, University of Antioquia School of Medicine, Medellín, Colombia

${ }^{4}$ Department of Neurology, Alder Hey Children's Health Park, Liverpool, UK

${ }^{5}$ Hopital Pitié-Salpêtrière / Sorbonne Université / Institut du Cerveau et de la Moelle, Paris, France

${ }^{6}$ Departments of Neurology and Pediatrics, Children's Hospital of Philadelphia, Philadelphia, Penn

${ }^{7}$ Institute of Clinical Neuroscience, Sahlgrenska Academy, Göteborg University, Göteborg, Sweden

${ }^{8}$ University College London, Great Ormond Street Institute of Child Health, and Great Ormond Street Hospital for Children, London

${ }^{9}$ Department of Pediatrics, McMaster University, Hamilton, Ontario, Canada

${ }^{10}$ Neurology Department, Cairo University, Cairo, Egypt

${ }^{11}$ Stollery Childrens Hospital and the University of Alberta, Edmonton, Alberta, Canada

${ }^{12}$ Institute of Medical and Biomedical Education, St George's University of London and The Atkinson Morley Regional Neuroscience Centre, St George's University Hospitals NHS Foundation Trust, London, UK

${ }^{13}$ Bodelschwingh Foundation Bethel, Bielefeld, Germany 
${ }^{14}$ Department of Functional Neurology and Epileptology, Hospices Civils de Lyon and University of Lyon, Lyon, France, Lyon's Neuroscience Research Center, INSERM U1028, CNRS UMR5292, Lyon, France

${ }^{15}$ Department of Psychiatry University of Cambridge, and Cambridgeshire and Peterborough NHS Trust. UK

${ }^{16}$ Department of Pediatrics \& Communicable Diseases, Division of Pediatric Neurology, Michigan Medicine, Ann Arbor, MI, USA

${ }^{17}$ Division of Pediatric Neurology, Department of Neurology, Amrita Institute of Medical Sciences, Cochin, Kerala, India

${ }^{18}$ Divisions of Child and Adolescent Neurology and Epilepsy, Department of Neurology, Mayo Clinic, Rochester MN USA

${ }^{19}$ Hôpital Necker Enfants Malades, Université Paris Descartes, Institut Imagine (INSERM UMR 1163)

Key Words: epilepsy, transition, adolescent,

Word count abstract 202

Word count body of paper 7697

References 62

Corresponding author: Peter Camfield MD, IWK Health Centre, 5850 University Ave, Halifax, Nova Scotia, Canada B3K6R8, email camfield@dal.ca

Supported by unrestricted educational grants from:

The funding sponsors had no input into the program and have not seen this manuscript prior to its publication. 


\begin{abstract}
Objective evidence is limited for the value of transition programs for youth with chronic illness moving from pediatric to adult care; however, such programs intuitively "make sense". We describe the strengths and weaknesses of a variety of transition programs from around the world for adolescents with epilepsy. Consequences of poorly organized transition beyond suboptimal seizure control may include an increased risk of SUDEP, poor psychological and social outcome and inadequate management of comorbidities. The content of transition programs for those with normal intelligence differs from those with intellectual disability but both groups may benefit from an emphasis on sporting activities. Concerns that may interfere with optimal transition include lack of nursing or social work services, limited numbers of adult neurologists/epileptologists confident in the treatment of complex pediatric epilepsy problems, institutional financial support, and time constraints for pediatric and adult physicians who treat epilepsy and the provision of multidisciplinary care. Successful programs eventually need to rely on a several adult physicians, nurses and other key health care providers and use novel approaches to complex care. More research is needed to document the value and effectiveness of transition programs for youth with epilepsy to persuade institutions and health care professionals to support these ventures.
\end{abstract}




\section{Introduction}

'Transition' is the purposeful, planned process that addresses the medical, psychosocial and educational/vocational needs of adolescents and young adults with long-term conditions as they move from child-centered to adult-oriented healthcare systems. 'Transfer' is the formal event when the healthcare of a young person moves from children's services to adults' services"1. This paper summarizes the third, two day symposium in France addressing transition to adult care for youth with epilepsy. The meeting took place in France in July 2018 and included 27 participants from France, Germany, UK, Italy, Canada, USA, Colombia, Egypt and India. The previous meetings were summarized in a supplement to Epilepsia in $2014^{2}$, and three summary papers in a supplement to Epilepsy and Behavior in $2017^{3,4,5}$. The current symposium focused on various models and realities for epilepsy transition as well as the costs and effectiveness of these programs. This paper summarizes the presentations and discussions along 5 themes - generic transition programs, transition programs for other disorders, existing epilepsy specific transition programs, the results of inadequate transition in epilepsy, and special issues for transition for youth with intellectual disability (ID). A second paper based on this symposium will address costs and will propose methods of evaluation for the process of transition.

Youth with epilepsy live with uncertainty. A seizure may occur at any moment and leave them with postictal confusion and incontinence. Learning is often impaired and school success relatively unlikely. Their peers may be friendly but often secretly fear that epilepsy is a contagious, horrible disorder. An elusive goal of pediatric care is to overcome these difficulties. AEDs prescribed during childhood are often ineffective and there is no reason to suspect they will be more effective in adulthood. Employment seems a reasonable aim, but despite legal protections, many employers are not supportive. Marriage implies a caring partner who can also deal with uncertainty. Learning difficulties preclude many professions and co-morbid depression and anxiety frequently cloud daily life. ${ }^{6} \mathrm{~A}$ transition program may provide a hopeful boost into adulthood although there is very little objective data that demonstrates the value of transition programs for any chronic disease in childhood. ${ }^{7}$ A systematic review in 2015 found 261 studies of interventions for transition, but there was limited overall evidence for effectiveness. ${ }^{8}$ A Cochrane review in 2016 found only four valid studies with a total of 238 participants - too few to draw conclusions. ${ }^{9}$

The goals for transition are rarely made explicit but three factors seem critical. ${ }^{10}$ First, provide youth with developmentally appropriate education about their epilepsy, clinical course and treatment. This leads to an expectation that the youth will learn to take personal responsibility and be able to do the things that successful adults with epilepsy need to do such as adhere to medication regimens, explain their disease to health care providers and peers, make appointments with appropriate health care providers, clearly articulate what is problematic for themselves, become independent in interacting with all 
aspects of adult medical care, and be able to assess when the health care system is letting them down and what to do about it. Second, provide information about the potential lifestyle changes such as restrictions for driving, employment and use of alcohol and other substances. Third, initiate and continue an ongoing relationship between the patient with epilepsy and his/her follow-up care providers to encourage lifelong engagement. The details of these goals will vary with cognitive ability and may be very truncated when intellectual disability is significant. The parents or guardians of these youth will need to be "transitioned".

How do we attain these deceptively simple goals? The ideal plan must encourage the patient to take charge of his/her life and see him/herself as a person with epilepsy rather than a dependent "epileptic". Self-confidence and self-esteem need to fostered from an early age - which can be enhanced in adolescents by having them take control of daily life with epilepsy such as finding ways to avoid missed doses, learning who pays for medications and doctor visits and how to negotiate the medical and insurance systems. How do they communicate their concerns to the doctor? What can they expect the doctor to do for them? What do they do if they do not understand what the doctor is telling them and how shall they remember what the doctor suggested that they do? What additional sources of information should they use to decide if their adult doctor or other health care provider is skilled, and what do they do if they perceive their care as inadequate. Transition and transfer to the adult health care system should be as seamless as possible and include an excellent, succinct summary of the past history and treatment. There needs to be reassurance that the adult system understands the epilepsy syndrome, best treatment and co-morbidities. Keeping an initial appointment in the adult world is critical and should be verified.

There is no single way to achieve these goals which must take into account the family's resources and location, the expectations of the patient and family, the capabilities of the young person with epilepsy and the social milieu. As well, it is also important to consider the geographic distance between patient's home and the pediatric and adult care providers, access to a case coordinator and/or an epilepsy nurse, and available community resources. There are a variety of programs that purport to help.

\section{Generic transition programs}

Generic transition programs have been developed in many centers. "Generic" means that they should apply to most chronic disorders in adolescence that are likely to persist into adulthood. Two generic programs were reviewed.

a) Ontario

An expert epilepsy transition task force in the Canadian province of Ontario suggested that such programs should be initiated at least 2 years before transfer to adult care and be the responsibility of the pediatric institution. ${ }^{11,12}$ An adult primary care provider for the youth (not a pediatrician) needs to be identified along with medical specialists. The ability of the youth to make independent autonomous decisions must be clarified and 
developed. Readiness for transition should be assessed for the youth, family, pediatric health care providers and appropriate community services. ${ }^{13}$ A "mirror" service model should be developed that outlines the youth's current treatment needs and then matches these with potential adult providers. A formal program like "MyHealth Passport" transition tool may be very helpful. This tool provides a summary of the diagnosis, treatments and concerns and is completed by the youth (along with help when needed).${ }^{14}$ A year before transfer, medical and other appointments with adult providers are set up, along with solutions for logistic issues such as transportation. Following transfer, the case manager confirms directly with the youth and family that the first visit in adult care has taken place and offers help resolve of any issues related to adult care.

\section{b) Nice Guidelines}

The NICE guidelines for transition suggest 9 key elements (see Table 1). ${ }^{15}$ A recent study has prospectively evaluated the importance of these key elements using a sample of 374 youth including 150 intellectually normal youth with type 1 diabetes, 106 with cerebral palsy and 118 with autism spectrum disorder without an associated mental health problem. ${ }^{16}$ Based on three annual interviews and standardized questionnaires only three of the NICE nine key elements were strongly associated with a good transition outcome - appropriate parental involvement, promotion of health self-efficacy and meeting the adult team before transfer. Appropriate parental involvement "in their child's care, but with changing responsibilities" was assessed by asking parents and youth separately if they thought that the level of involvement was appropriate. "Involvement" considered if the parent was present at a typical clinic visit and if the parent or youth did most of the talking. Promotion of health self-efficacy was assessed in part by asking the youth "Have you received enough help to increase your confidence in managing your condition?" Meeting the adult team before transfer could be in one of three settings: a joint clinic with both pediatric and adult healthcare professionals, an appointment in the pediatric center that included an adult physician, or an appointment in the adult clinic at which the youth was accompanied by a key worker from the pediatric clinic. The implication of this very important study is that all epilepsy transition programs should incorporate these three features.

\section{Disease-specific transition programs for disorders other than epilepsy}

Many transition programs have been developed for specific chronic disorders other than epilepsy, but few have been well evaluated. Programs for renal transplant and type 1 diabetes stand out, because they have measurable objective outcomes (kidney rejection and Hemoglobin A1C (HbA1c) blood levels) that are not so evident in epilepsy. There are at least two studies that show the value of a transition program for youth with kidney transplants. ${ }^{17,18}$ Both found that without a transition program about one third of youth with a transplanted kidney lose their graft shortly after transfer to adult care, presumably as the result of poor adherence to immunosuppressive medications and/or 
the loss of medical follow up. In both studies, the introduction of a transition program was associated with virtually no loss of grafts.

Transition programs for type 1 diabetes have been more frequently evaluated compared to other chronic conditions. A meta-analysis in 2017 identified a number of controlled trials involving 3382 youth with diabetes. ${ }^{19}$ All of the studies showed maintenance or improvement in $\mathrm{HbA} 1 \mathrm{c}$ levels in patients with a transition program, although this was not different than controls one year after transition. It seemed that pediatric care was reasonably effective, although transition programs were associated with reduced rates of ketoacidosis or severe hypoglycemia during young adulthood.

Transition programs for neurological disorders have been described, particularly for conditions for which advances in treatment has led to longevity in adulthood. The Spina Bifida Association has outlined the most critical stages in transition, although many American clinics lack comprehensive programs.$^{20}$ For example, they report that only $30 \%$ "communicate with the adult providers". Duchenne dystrophy has been most frequently studied. At least $40 \%$ of boys with Duchenne muscular dystrophy are now alive at 40 years of age and their care needs are increasingly complicated with extended life span. ${ }^{21}$ In Japan, most adults with this disorder live in one of 27 specialized wards that provide comprehensive care for patients with Duchenne dystrophy. ${ }^{22}$ This model of care would not likely be acceptable in countries where living at home or in a community setting is strongly valued. For the past 10 years, a network of specialists in Paris voluntarily, without remuneration, meets monthly (on a Saturday morning!) to work out transition needs of complex patients with neuromuscular conditions. Dedicated clinicians deemed it necessary as there is no established program to accomplish this important task during the work week, and there is often a significant physical distance between pediatric and adult care institutions. Advances in other neurological disorders are allowing children with formerly lethal disorders of childhood to live for unprecedented survival, and for which adult neurologists may not be prepared. Spinal muscular atrophy is an example of the new demands on adult neurology as genetic treatments create, in a sense, "prolonged palliative care".

Many centers use a generic transition program modified with epilepsy specific modules starting between ages 12 and 14 years of age. This is based on strong evidence that youth at this point have the ability to understand the principles of self-management and the developmental skills to self-advocate. This is also the age in the US for which initiation of transition is mandated in the educational system for children with special needs. The process is then completed in a transition/transfer clinic at age 16-21 years of age.

Transition programs specifically for epilepsy United Kingdom 


\section{a) Liverpool}

The NICE Quality Standard Statements on young people with epilepsy emphasize that "Young people have an agreed transition period during which their continuing epilepsy care is reviewed jointly by pediatric and adult services". ${ }^{23}$ This statement was based on the examples of joint epilepsy transition clinics well described first in Liverpool ${ }^{24}$ and then replicated to some degree in Wales. ${ }^{25}$ These clinics are staffed jointly by a pediatric and an adult epilepsy specialist and an adult epilepsy nurse. Patients are seen jointly for several visits until the transition team judged that the young person was ready to be cared for in the adult setting.

This format has some major strengths - epilepsy is the focus of the clinic and care and management is expert. Most patients will have been cared for by the same pediatric neurologists that are part of the transition team, allowing continuity of care through the transition process. There is no fixed age for transfer to an adult service, and there is sufficient time for youth and their families to develop a rapport with the adult epilepsy team and environment. On the downside, this format does not readily address comorbidities such as intellectual disability or autistic spectrum disorder; although access to mental health and intellectual disability services should be available. There is the additional scheduling burden and cost associated with both pediatric and adult epileptologists seeing the patient at the same time, and the frequency of clinics is only monthly. This service has not been formally endorsed by the adult and pediatric Hospital "Trusts" (administrative entities in the UK). Convincing evidence of the value of such services is difficult to produce and ongoing commitment of key personal may be an issue.

In 2011, a UK wide survey identified 15 centers that indicated that they had a form of transition program defined as "a clinic or service that provides joint paediatric and adult supervision of care from paediatric to adult services. ${ }^{26}$ Most centers were tertiary with no epilepsy transition programs at the secondary or primary care level. The programs varied between centers with six having no nursing support. Patients were transferred on to adult care after a single assessment in seven (47\%) centers, at a fixed age of 18 in four centers or in a flexible manner that was deemed patient-dependent in four.

\section{b) Great Ormond Street, London}

There is considerable emphasis at Great Ormond Street Hospital on a transition program that begins in early adolescence and is based on the Ready Steady Go process and generic guidelines from NICE. ${ }^{15,27}$ Transfer to adult services occurs by age 17. In addition, starting at age 12 for those with normal intelligence, a series of "teenage talks" begin with the nurse clinician to cover a series of specific, epilepsy related issues. There are 12 overarching goals (see Table 2) for transition readiness and at each clinic visit one or more goals are selected to be achieved by the next clinic. For patients with 
intellectual disability the list of goals is modified but with the emphasis on as much independence as possible (Table 2).

Most patients are eventually transferred to the existing adolescent clinic at the National Hospital for Neurology and Neurosurgery (NHNN) at Queen's Square. There are several specific adult clinics that accept transfers from the pediatric service including youth with Dravet Syndrome, metabolic disorders, epilepsy surgery, vagus nerve stimulator, and tuberous sclerosis. There are major problems to find adult services for youth continuing treatment with the ketogenic diet. Disorders such as Sturge Weber syndrome and Rasmussen syndrome also do not have a designated clinic to transfer to but remain in the complex Epilepsy service.

At the time of transfer there is a one visit "hand off clinic" with joint attendance of a pediatric specialist and the adult epilepsy team. A decision is then made as to whether continuing transition should be through a more local service, transfer made to a specialist clinic or care continued for a short time through the transition clinic itself.

\section{Canada}

a) Edmonton, Alberta

A nurse-led program in Edmonton, Alberta has been well-described. ${ }^{28}$ Once a decision is made to transfer a young person with epilepsy to the adult epilepsy service, the pediatric and adult epilepsy nurses meet with the youth and family to discuss a series of topics that are individualized and in part determined by a transition readiness questionnaire. These sessions may be delivered via telehealth because of the enormous distances in the catchment area. Topics covered include seizure type, first aid for seizures, status epilepticus, medications and their side effects, seizure triggers, work/school/finances, driving, women and epilepsy, alcohol and drugs, home safety, nutrition/exercise, bone health and community resources. The nature of the adult service (including differences from the pediatric model) is discussed with the eventual goal of the adolescent becoming as independent as possible in managing his/her own health care with ongoing nursing support as needed in the adult program, a goal that may take a long time to achieve.

For patients with intellectual disability, topics also include guardianship, trusteeship, income support, day programming, independent living, group homes and in-home care. Throughout the program, there is an emphasis on independence for the young person and support for the family. To date 662 young people have benefitted from the program. Families seem to be very satisfied with the program, and because youth with epilepsy are now so much better prepared, the adult epilepsy program has made this transition program mandatory before transfer - a striking endorsement.

\section{b) Halifax, Nova Scotia}


A joint pediatric-adult transition clinic was developed with two pediatric neurologists, one adult epileptologist and an adult epilepsy nurse ${ }^{29}$ This clinic was described in a publication that included details of a comprehensive medical summary prepared by the pediatric neurologists and a comprehensive social summary completed by the patient with help from the family. ${ }^{29}$ Patients were seen in the adult setting. For the initial visit the history was reviewed with the pediatric neurologist, adult neurologist, adult epilepsy nurse and the patient and family. The adult neurologist and nurse then met for an hour with the patient alone if he/she was cognitively normal; the family was included if there was associated intellectual disability. Then the pediatric neurologist rejoined the group for a discussion of future plans. One or two follow-up visits were scheduled with the pediatric and adult neurologist and epilepsy nurse. Thereafter, the adult service took over completely. The clinic seemed to function well, although there was inadequate work space for the pediatric neurologist when the patient was being seen by the adult service. Punctuality was a problem. About 50 patients were transitioned but then the two pediatric neurologists retired from clinical practice and the remaining pediatric neurologists at this center chose not to continue the clinic based mainly concerns that the process was too time consuming.

\section{c) The Hospital for Sick Children (HSC), Toronto and the Toronto Western Hospital}

The HSC - Toronto Western Hospital transition program began in 2007. Patients with epilepsy are prepared for transition with the generic Good2Go program, a personalized "health passport" and a Transition Readiness Questionnaire that is prompted by the electronic health record at clinic visits before 18 years of age. ${ }^{14,30} \mathrm{~A}$ medical summary is usually prepared by the pediatric service. The actual clinic consists of a single visit at HSC attended by the pediatric epilepsy nurse and the adult epileptologist along with a volunteer from the Epilepsy Toronto Adolescent Group. Four new patients are seen at each clinic. ${ }^{31}$ Since 2014, the visits have also been staffed by both adult and pediatric social workers, the adult nurse practitioner and an adult epilepsy genetics fellow. All further visits are in the adult setting with the adult epilepsy physician.

Several one-page handouts related to finances, social interactions, education, housing, respite support, employment and health insurance are prompted by the electronic medical record. They are given to patients and families during the pediatric epilepsy care visits. An adult ketogenic diet clinic was established to care for patients who continued to benefit from the ketogenic diet. A concern for this clinic is that it currently only involves a single, dedicated adult epileptologist. Expanding the pool of adult epileptologists/neurologists who are comfortable with pediatric onset epilepsy is a priority.

\section{Sweden (Goteborg)}


Patients with epilepsy in Sweden have access to a wealth of support services including social, habilitation therapies and income. Many of the difficult issues in other countries seem to be managed relatively easily in Sweden, such as income support or housing for intellectually disabled youth. In addition, there is a well-functioning universal comprehensive electronic medical record. The exact nature of transition programs vary with location; however, there is a systematic attempt to be sure that by the mid-teenage years youth with chronic disease understand both their disorder and the adult health care system that will eventually care for them. In Goteborg, there is a biannual meeting between pediatric and adult neurologists who care for children with epilepsy to discuss the best care setting for each patient who is approaching transfer. Care for comorbidities is also arranged. Some patients have adult follow up with family physicians only, if for example they are seizure-free. For those moving to adult epilepsy services, the first visit with the adult neurologist lasts one hour and includes an introduction to the epilepsy nurse. Within a month there is a second visit with the nurse at which time there is introduction to the social worker and psychologist. A major dilemma for the wellcontrolled patient is decision making about continuing AED treatment. The adolescent must decide at this point; practical issues such as retaining a driver's license are often more important than the risk of relapse after AED discontinuation. The presenter for this section suggested several key questions that adult epileptologists should ask of their newly transferred patients. These included: What do you know about epilepsy? Do you know anyone else who has epilepsy? Do you know what your seizures look like? Who knows that you have epilepsy? Do you tell other people about your disorder? What would your friends do if you had a seizure? Do you think you have side effects? Everyone forgets to take their meds....Do you? Discussions about alcohol, sex and contraception, driver's license and choice of career are considered very important, and discussed candidly.

France,

\section{a) Necker Hospital, Paris}

In France, under the rare diseases program, there are eight reference centers for epilepsy and 20 additional centers considered to have special competence in epilepsy care. The reference center at Necker Hospital in Paris has a transition program beginning at age 14 years with emphasis on parent and patient education. This focuses on seizures, cognition and learning, psychiatric and behavior disorders, motor abilities, sleep problems, nutritional disorders, therapies (efficacy and side effects) and social competence. ${ }^{32} \mathrm{~A}$ list of the adolescent's services is then mirrored for transfer to the adult services. For adult epilepsy care, most transfers are to la Pitié-Salpêtrière reference center, where a single, dedicated epileptologist works within the rare disease network. A very high proportion of transferred patients have co-morbid intellectual disability.

To assist the young person through the transition/transfer process there is a unit in Necker called "La Suite". This is an area for patients only; parents are not allowed. "La 
Suite" includes social workers, a sport coach, educators, make up specialists, hair dressers as well as special medical clinics that include dermatology, primary care physicians, gynecology, endocrinology, occupational and physiotherapy and nutrition.

\section{b) Pitié-Salpêtrière Hospital}

In the Pitié-Salpêtrière Hospital, there has been a bold attempt to replicate the multidisciplinary nature of pediatric care. The "Jump Program" is a unit within the hospital for young adults with complex disorders. ${ }^{33}$ Carefully screened patients are admitted for a single day with multiple disciplines scheduled to assess the patient. At the end of the day a tailored program for follow up is implemented, including subspecialists and allied health professionals. An evaluation of 133 consecutive patients (average age 19.7 years, range: $15-36$ ) showed high levels of patient/family satisfaction with this program. ${ }^{33}$

\section{Germany, The MOSES Program, Bethel}

The Modular Service Package Epilepsy (MOSES) program is an interactive educational program for late adolescents or adults with epilepsy and is applicable to all people with epilepsy regardless of epilepsy syndrome, severity or duration of epilepsy. ${ }^{34}$ The program is delivered by trained instructors in 14 lessons that each last about one hour. Major themes are: improving knowledge about epilepsy and its psychosocial consequences, coping with epilepsy and associated emotions, seizure management and seizure triggers, self-management, self-responsibility (active role within treatment), improving communication skills, and living with as few limitations as possible.

MOSES can be used gradually in clinical care or as an intensive two day workshop in groups of 6-14 participants. Although not specifically designed as a transition tool, it has been subjected to a randomized clinical trial with the treatment group enrolled immediately in a two day course and compared to the control group randomized to a waiting list for six months before receiving the MOSES program. ${ }^{35}$ The study involved 242 randomized patients at 22 German speaking centers. Patients had a wide variety of epilepsy syndromes, seizure severity and co-morbidities. Six months after the intervention, seizure control, knowledge about epilepsy and a measure that assessed "coping with epilepsy" were significantly better in the treatment group. The latter is particularly relevant for transition. The MOSES program has been translated into Japanese, Czech, Lithuanian, and English and is continuing to be updated and modified. For example, recently a module on SUDEP has been included. In addition, there is a separate program to certify instructors in MOSES.

MOSES would seem to be a very valuable program to boost the knowledge and transition readiness of late adolescents with epilepsy. There is another similar, evaluated program ("FAMOSES") for younger children with epilepsy ages 8-12 years 
and their parents. ${ }^{36}$ Parents significantly improved in their epilepsy-specific knowledge, coping, epilepsy-related fears, and in speaking about epilepsy with their child compared with the control group. All of these factors are relevant for transition.

\section{Transition in less advantaged countries}

\section{Colombia}

In Colombia a national law was enacted in 2010 that appears to guarantee access to care for all people with epilepsy; however, this has not lead to direct improvements in care. Only one of the 56 medical schools includes transition as topic for teaching. In 2017, The School of Medicine of the University of Antioquia in Medellin introduced a one-week teaching course about transition that includes theory and practice for a variety of chronic illnesses in children, including epilepsy. It has been difficult to persuade insurance companies to pay for "healthy medical appointments" for adolescents with chronic disease.

India

Health care varies a great deal across India, an enormous country with a population of 1.35 billion. Primary care remains the biggest focus in the public health care system along with maternal - child health and immunization services. A mixture of corporate, private and charity institutions provide some secondary and tertiary services especially to those who are financially advantaged. The 50,000 pediatricians throughout the country act as primary care or epilepsy consultants, but there are very few trained pediatric neurologists. This means that most of the epilepsy care for children and adolescents is delivered by family physicians, adult neurologists or psychiatrists. For those followed by adult neurology there is no gap in physician care in later adolescence; however, there are no programs to help a young person with epilepsy to become more independent within a system where the neurologist does not change. Moreover, adult neurology services are not equipped to provide comprehensive care for patients with ID. As pediatric neurology develops as a specialty in India, there is a real opportunity to develop transition programs that have no historical constraints.

\section{Egypt}

In Egypt, a country of nearly 100 million, there are only two academic medical centers. Throughout the country, services for children with epilepsy are sparse with few epileptologists. Most expert epilepsy care is by pediatric and adult neurologists, neurosurgeons and psychiatrists. Comprehensive care for childhood epilepsy is limited and there is concern about accuracy of diagnosis. Transition to adult care appears not to be an important priority at this point. 


\section{Other activities that may improve transition/transfer success}

Many activities for youth that are not specifically centered on transition may have beneficial effects on maturity, socialization and independence; although, these programs/activities have not been rigorously established to be of benefit. One of these is participation in sports

Basic research in animal models has shown that physical activity can prevent epileptogenesis and reduce seizure frequency, duration and intensity in established epilepsy. ${ }^{37}$ The proposed mechanisms are wide and include: a) release of betaendorphins from the opioid system, b) release of steroids, c) increase in melatonin concentrations d) increase of antiepileptogenic and cytoprotective parvo albumin e) reduction in hyperreactivity of $\mathrm{CA} 1$ cells and generation of structural changes within the hippocampus, f) enhancement of the inhibitory effect of noradrenaline and GABA released during exercise, $g$ ) increased antioxidative mechanisms that decrease epileptogenesis, $h$ ) increased density of new blood vessels as a mechanism to decrease excitotoxicity, and i) release of neuroprotective trophic factors and expression of neuronal growth factors.

Despite these benefits, data from Finland, Canada, several sites in Midwestern USA, Norway, Brazil, Thailand and Korea all show that physical activity is decreased in people with epilepsy compared with controls. ${ }^{38}$ Medical advice to participate in sports was offered less frequently to those with epilepsy and sometimes even discouraged by teachers, instructors and physicians. Avoiding exercise was based in part on recommendations from relatives, friends and physicians with the additional factors of fear and embarrassment of having a seizure in public, lack of time or motivation, fatigue, absence of sporting companions and concern that exercise might precipitate seizures. ${ }^{36}$ The 2010 National Health Survey in the United States reported that in preceding week only $39 \%$ of people with epilepsy had walked for $\geq 10$ minutes per day, compared to $50 \%$ of the general population. ${ }^{39}$ Not surprisingly, another study indicated that compared with siblings, adolescents with epilepsy were less likely to be involved in sport groups or engaged in physical activity, and more likely to be overweight and obese.$^{40}$ On the positive side, people with epilepsy in Arizona who had regular physical activities had fewer activity limited days. ${ }^{41}$ Physical activity has been demonstrated to have an incredible range of beneficial effects including improvements in cardiovascular fitness, musculo-skeletal wellbeing, posture, osteoporosis, depression and anxiety, selfimage, vitality, neurocognitive function (attention, psychomotor speed, impulse control, inhibition/ disinhibition, problem-solving skills), social competence and overall quality of life. In terms of epilepsy there is some suggestion that regular exercise is associated with better seizure control, fewer EEG epileptiform discharges and a decrease in the risk of SUDEP. ${ }^{36}$ Based on this mass of data, it seems likely that encouraging sports and exercise is a very worthwhile aspect of transitional care for youth with epilepsy. ${ }^{42}$

\section{What happens if transition for epilepsy is poorly managed?}




\section{SUDEP (Sudden Unexpected Death in Epilepsy)}

As noted above there are few evaluations of transition programs for any chronic disease. To date we are unaware of evaluations of epilepsy transition programs that address such critical issues as seizure control, episodes of status epilepticus, SUDEP, management of co-morbidities or impact on family life. The major risk factors for SUDEP are drug-resistance, presence of generalized tonic-clonic seizures and most importantly, a high frequency of generalized tonic-clonic seizures. ${ }^{43}$ Much of the literature to date has suggested that the rate of SUDEP in childhood is lower in children than in adults, ${ }^{44}$ although a long term follow up study of a Finnish cohort suggest that the rate of SUDEP rises as epilepsy persists from childhood into adulthood. ${ }^{45}$ In 2018 , a study from the Province of Ontario, Canada identified 16 cases of definite or probable SUDEP in children over a one year period. ${ }^{46}$ Based on an estimate of the prevalence of epilepsy in the Province, the authors suggested that the risk of SUDEP was 1.11 per 1000 pediatric epilepsy person years with a wide confidence interval (0.63-1.79). This risk is close to the usual risk quoted for adult epilepsy. Of course, this is the risk for prevalent cases of epilepsy - the risk for incident cases is much lower in populationbased studies [0.33/1000 patient years (range 0.13-0.53)]. ${ }^{43}$ In addition, a large study from Sweden of 57,775 people with epilepsy found the incidence of SUDEP (again in prevalent cases) to be similar across the ages ${ }^{47}$ From the perspective of transition, it would seem prudent to consider SUDEP as an important topic to emphasize as the youth takes responsibility for factors in their control to concentrate on the importance of good seizure control.

\section{Comorbidities}

Comorbidities associated with epilepsy at any age may be more problematic than the seizures. Management of ADHD, anxiety disorder and depression through the transition ages seems particularly important for a good quality of life in adulthood. From the perspective of transition, we reviewed other co-morbidities such as sexual dysfunction and bone mineral health during the 2016 Paris transition conference.$^{5}$ In addition to biological factors, psychiatric co-morbidities in people with epilepsy have been related to the chronic nature of epilepsy, low educational level of youth with epilepsy, high rates of unemployment or underemployment, difficulties in adjustment to consequences, fear of seizures and their unpredictable nature, social stigma, overprotection by families, legal limitations (especially driving regulations), and low self-esteem. ${ }^{48}$ It has been estimated from a prevalence cohort study of children and adolescents with active epilepsy aged 515 years that $40 \%$ have intellectual disability, $33 \%$ have ADHD and $21 \%$ have autistic spectrum disorder. ${ }^{49} \mathrm{ADHD}$, if undiagnosed and untreated, is associated with an increased risk of developing a major psychiatric disorder in adulthood. Further ADHD seems to have some special features when it is associated with epilepsy. The male/female ratio is close to one and there is an increased chance of inattentive presentations. Still, it is well established that outside of epilepsy, about $50 \%$ of adults with depression had an anxiety disorder in childhood. Based on all of these concerns it 
is important to screen for and initiate treatment for psychiatric disorders around the time of transfer to adult care for youth with epilepsy.

Family function will be affected by failure to deal with many transition issues. Social outcome of childhood onset epilepsy with normal intelligence has been well studied. Approximately $70 \%$ of children followed $>20$ years have $\geq 1$ serious adverse social outcome: incomplete education, unemployment, a formal psychiatric diagnosis other than ADHD, extreme isolation with no friends, no romantic relationships, living alone and inadvertent pregnancy. ${ }^{6}$ These studies were carried out before formal transition programs had been developed. It is likely that multiple factors contribute to these problems including poor seizure control, onset at a very young age, cognitive problems, low socioeconomic status, low parental education, poor family function, poor intervention services, low self-esteem and lack of role models in family, school or society.

Each one of these adverse social outcomes will obviously affect the social network supporting each young adult. Poor education leads to low rates of employment and prolonged dependency. Social isolation potentially means that the family continues to be over-involved in every aspect of the youth's life, and inadvertent pregnancy may lead to even greater dependency.

Finally suicidal thoughts and attempts should be screened for in adolescents with epilepsy, especially for those with special risk factors including depression, depression

in relatives, polytherapy, refractory epilepsy, substance abuse or epilepsy surgery. ${ }^{50}$

\section{Managing epilepsy during late adolescence (16-21 years)}

As emphasized throughout the transition literature, the process of transition ideally begins around age 12 and continues until transfer to adult care which is usually between ages 16 and 21. Special issues arise in the last few years of the transition process, with major differences for those with normal intelligence and those with ID.

\section{Managing epilepsy during late adolescence (16-21 years) with normal intelligence}

Most teens with epilepsy and normal intelligence in the process of transition to adult epilepsy care have Genetic Generalized Epilepsy or Focal Epilepsy from a discrete lesion or an unknown cause. Prior to transfer, the pediatric neurologist should reevaluate the diagnosis and treatment, ensuring up-to-date investigations (genetic, imaging and autoimmune) and best current treatment (optimal AEDs, minimal polytherapy, potential surgery). The goals of transition are fairly straight forward.

Education over the later part of the transition period should take into account the stage of cognitive development. Early teens are more concrete thinkers and are still exploring their sense of identity. ${ }^{51}$ They may have greater challenges with denial of illness and comprehending cause and effect, such as the consequences of poor compliance. By mid-late adolescence, teens are refining their established sense of identity, and are capable of more abstract thinking. ${ }^{51}$ 
When available, epilepsy nurses can capably provide much of the education. Checklists can ensure the content is complete and mastered by the adolescent. In addition to basic information about epilepsy, late teens should be encouraged to raise concerns regarding AED side effects and discuss strategies to improve compliance. They need to understand potential seizure triggers, risk of seizures including SUDEP, their emergency plan and who and when to call if their clinical state deteriorates. Given the high risk of unplanned pregnancy in adolescents, ${ }^{52}$ females should be aware of the pregnancy and hormonal concerns of AEDs and the need for folate supplementation. Long-acting, reversible contraceptive methods including injections, intrauterine devices or subdermal implants are very effective and well-tolerated. Interactions between oral contraceptives and AEDs need to be well understood. Adolescents have longer endogenous and delayed circadian rhythms, which are exacerbated by excessive screen time before bed - anticipatory guidance to maximize sleep hygiene seems worthwhile although changing these "addictions" may be difficult. Adolescence is a high risk period for the presentation or exacerbation of many psychiatric disorders which significantly impact quality of life, including ADHD, depression and anxiety. These often co-exist, and are can be very treatable if recognized. ${ }^{53-55}$ Adolescents must understand the local regulations regarding driving. AED weaning in seizure-free teens with possible self-limited epilepsies should ideally take place prior to the legal driving age. Social issues to be addressed include access to medical insurance, occupational and higher education plans and identification of social supports.

Experimentation with alcohol, cannabis and other substances is common at this age and should be discussed.

While there is increased focus on the teen during this period, parents need to understand the goals and process of transition as well as normal adolescent cognitive development. They should be encouraged to address their concerns about the increasing independence of their teen with epilepsy.

\section{Managing epilepsy during late adolescence (16-21 years) with ID}

The special issues that complicate the lives of patients with epilepsy and ID depend on the exact age of transfer and the jurisdiction. It is best to conclude formal arrangements about decision making (legal guardianship) before the youth with ID moves to adult care; however, it is mandatory once the youth reaches the "age of majority" for their jurisdiction. If the age of majority comes after the age of transfer to adult care, then there is a temptation to leave the definition of who makes decisions to the adult health care system. The process to establish capacity for decision making is a legal one and physicians who provide expert advice about a patient's capacity may find that they are required to complete extensive paperwork or appear at a legal proceeding. This can be a time consuming and unwanted activity.

There are a multitude of other social issues that need to be addressed for the late adolescent with epilepsy and ID. Social support services often change at the end of 
childhood. When school ends there may be little or no organized activities outside the house and no respite care for parents. ${ }^{56}$ In some countries a several year gap in services is not unusual between the end of childhood ( age 18 and the beginning of adulthood age 21). These problems may lead to a major mismatch between parent and physician priorities. We are of the opinion that the among the highest parental concerns are often behaviour management, long-term placement in a facility such as a group home, legal processes to obtain guardianship and power of attorney, respite care, management of menstrual cycles and regulation of sleep. Physician priorities are more likely to include seizure control (often very challenging in this group), etiology, identifying an adult health care provider, behavior management, general health maintenance and avoiding excessive extra work. Dealing with these challenges beyond control of seizures presents dilemmas. It is clear that leaving all of the social issues to be resolved by the pediatric or adult epileptologist is unlikely to be successful physicians lack the time and often the knowledge to deal with these problems. A multidisciplinary approach that includes social work, nursing and/or a transition coordinator is needed. Admittedly, it may be difficult to convince health care administrators of the need for such an expensive undertaking that does not match the usual, simple model of doctor-patient relationships. It is difficult to demonstrate that these extra efforts that seem so valuable are actually cost effective, particularly in a medical care environment such as the United States where profit motives are so prominent. Cost effectiveness issues for transition are dealt with in the subsequent paper from this symposium. Parent advocacy groups and political pressure may be required to improve the adult life of patients with epilepsy and ID. Observational studies suggest that adult life for patients with epilepsy and ID is often quite unsatisfactory for both the parent and family. ${ }^{57}$

In addition young adults with epilepsy and ID often had diagnostic evaluations prior to the current revolutions of genetic testing and more advanced neuroimaging. Before transfer to the adult healthcare system, we suggest that the pediatric providers review any completed evaluations and consider additional tests to define the etiology for those whose epilepsy has not clear cause. In many cases the pediatric healthcare system has specific resources for completing such testing with developmentally appropriate supports (e.g. child life services) or access to pediatric anesthesia.

\section{What happens to adolescents with epilepsy and intellectual disability?}

There is very little specific information about the adult life of patients with epilepsy and ID. One study identified 183 adults with epilepsy and ID (average age of 40, range 1672) from a single county in the UK ${ }^{58}$ Most had childhood onset epilepsy. Epilepsy care was provided by a hospital-based neurology service in $37 \%$, by the general practitioner in $67 \%$ (sometimes in combination with the hospital-based neurology service), and by the Community Intellectual Disability Team in 91\% (CIDT). The CIDT teams do not include a neurologist but may include a psychiatrist with expertise in epilepsy and/or a 
nurse with special training in epilepsy. Overall, a neurologist was involved in epilepsy care in only $54 \%$.

In a second UK-based cross-sectional study of 90 adult patients age $\geq 18$ years with epilepsy and ID living in the community compared patient characteristics and outcomes between hospital-based neurology services and community intellectual disability services ${ }^{59}$ Most of the patients had intractable epilepsy, yet epilepsy variables did not predict which clinical service managed their epilepsy. Patients with neurological comorbidities were more likely to receive hospital-based services and those with psychiatric comorbidities were more likely to receive CIDT services for epilepsy control. Living at home predicted hospital-based services. For $18 \%$ there was confusion about who was leading the epilepsy care, yet QOL did not differ amongst the groups.

The implications of these two studies for transition is that it may not be clear who will be providing adult epilepsy care. Preparing the family for this ambiguity might be helpful. We suspect that similar unevenness in epilepsy care for adults with ID exists in many countries. There are likely many patients with ID who receive less than expert epilepsy care.

\section{Conclusions}

There are a variety of programs for transition from pediatric to adult care for young people with epilepsy. Although all of these models "make sense", none have been proven to be of value, in part because there are no available metrics that determine success. All of these programs acknowledge the intense and rapid changes that occur during adolescent cognitive development that can impact epilepsy management including poor understanding or motivation to alter lifestyle to deal with factors such as sleep deprivation, alcohol, drugs, or treatment compliance. Models address the fact that teenagers with epilepsy are at increased risk of unwanted pregnancy, driving difficulties, unhealthy life styles, depression, and anxiety. Leaving the pediatric system also means moving from the "family-oriented" care offered at pediatric centers to the "patient-oriented care" offered in the adult health system. Learning how to be a successful patient in the adult system is central to many models. Ideally, epilepsy transition teams should have expertise in meeting the psychosocial needs of young adults with chronic epilepsy. Dedicated epilepsy nurses can improve communication with patients and families. A variety of strategies appear to solidify the patient's knowledge about his/her own condition and include tools such as "My Health Passport". ${ }^{14}$ Epilepsy agencies and family support groups may also offer social events to improve social or job finding skills.

Patients with epilepsy plus intellectual disability (ID) are at increased risk of unsuccessful transition. The reasons are complex and include confusion among multiple heath care providers and rare epilepsy syndromes not familiar to many neurologists. Patients with ID may have difficulty cooperating for investigations such as blood work, 
EEG and MRI that may lead to better epilepsy control. Adult hospital staff may not be well equipped to work with patients who cannot behave as expected for their chronological age or who need sedation for studies. ${ }^{60,61}$ Finally, compared to the pediatric system, the adult health system may offer less supportive care beyond the treating specialist. There is an important role in adult care for a very engaged primary care physician who can provide a "medical home." Ideally, this physician will be very familiar with the patient, understand epilepsy and ID and is able to co-ordinate care ${ }^{62}$ Organized multidisciplinary care approaches in adult medicine are uncommon, but programs like "Jump" are helpful models. ${ }^{33}$ Epilepsy community agencies and family support groups may assist with financial, social and legal support. ${ }^{61}$

Despite these barriers, many centers have developed transition plans that at least attempt to ensure that all patients with epilepsy leave the pediatric system with a diagnostic re-evaluation, an updated treatment plan, a current emergency plan and a careful documentation of comorbidities. ${ }^{62}$

Nearly all participants in this symposium agreed that it remains challenging to find adult neurologists who are comfortable with the increasing number of unusual pediatric epilepsies treated with novel drugs, neurostimulation or special diets. Many large transition programs depend on the expertise of a single adult neurologist; a vulnerable arrangement. Including transition services in epilepsy and neurology training programs will be increasingly important.

\section{Acknowledgements}

We thank Professor Isabelle Desguerre for her contribution to the discussion about transition programs and clinics for neuromuscular disorders. 


\section{References}

1. Blum RW, Garell D, Hodgman CH, Jorissen TW, Okinow NA, Orr DP, et al. Transition from child-centered to adult health-care systems for adolescents with chronic conditions. A position paper of the Society for Adolescent Medicine. J Adolesc Health. 1993;14:570-6.

2. Transition of epilepsy care from children to adults. Epilepsia. 2014;55 Suppl 3:1-53.

3. Nabbout R, Andrade DM, Bahi-Buisson N, Cross H, Desquerre I, Dulac O, et al. Outcome of childhood-onset epilepsy from adolescence to adulthood: Transition issues. Epilepsy Behav. 2017;69:161-169.

4. Nabbout R, Camfield CS, Andrade DM, Arzimanoglou A, Chiron C, Cramer $\mathrm{JA}$, et al. Treatment issues for children with epilepsy transitioning to adult care. Epilepsy Behav. 2017;69:153-160.

5. Camfield P, Camfield C, Busiah K, Cohen D, Pack A, Nabbout R. The transition from pediatric to adult care for youth with epilepsy: Basic biological,sociological, and psychological issues. Epilepsy Behav. 2017;69:170-176.

6. Camfield PR, Camfield CS. What happens to children with epilepsy when they become adults? Some facts and opinions. Pediatr Neurol. 2014;51:1723.

7. Wright C, Steinway C, Jan S. The genesis of systems of care for transition to adulthood services: emerging models in primary and subspecialty care. Curr Opin Pediatr. 2018:30:303-310.

8. Chu PY, Maslow GR, von Isenburg M, Chung RJ. Systematic Review of the Impact of transition interventions for adolescents with chronic illness on transfer from pediatric to adult healthcare. J Pediatr Nurs. 2015;30:e19-27.

9. Rachas A, Lefeuvre D, Meyer L, Faye A, Mahlaoui N, de La Rochebrochard, et al. Evaluating continuity during transfer to adult care: A Systematic Review. Pediatrics. 2016;138. pii: e20160256.

10. Nandakumar BS, Fardell JE, Wakefield CE, Signorelli C, McLoone JK, Skeen J, et al., ANZCHOG Survivorship Study Group. Attitudes and experiences of childhood cancer survivors transitioning from pediatric care to adult care. Support Care Cancer. 2018;26:2743-2750.

11. http://www.pcmch.on.ca/health-care-providers/paediatric-care/pcmchstrategies-and-initiatives/transition-to-adult-healthcare-services/ (accessed August 18,2018). 
12. Andrade DM, Bassett AS, Bercovici E, Borlot F, Bui E, Camfield $P$, et al. Epilepsy: Transition from pediatric to adult care. Recommendations of the Ontario epilepsy implementation task force. Epilepsia. 2017;58:1502-1517.

13. Klassen AF, Grant C, Barr R, Brill H, Kraus de Camargo O, Ronen GM, Samaan MC et al. Development and validation of a generic scale for use in transition programmes to measure self-management skills in adolescents with chronic health conditions: the TRANSITION-Q. Child Care Health Dev. 2015;41:547-58

14. https://www.sickkids.ca/myhealthpassport/ (accessed August 18,2018)

15. National Institute for Health and Care Excellence (NICE). Transition from children's to adults' services for young people using health or social care services, Guideline 43. London: National Institute for Health and Care Excellence (NICE); 2016. https://www.nice.org.uk/guidance/ng43/evidence/full-guideline-pdf$\underline{2360240173}$ (accessed August 18, 2018)

16. Colver A, McConachie H, Le Couteur A, Dovey-Pearce G, Mann KD, McDonagh JE, et al. Transition Collaborative Group. A longitudinal, observational study of the features of transitional healthcare associated with better outcomes for young people with long-term conditions. BMC Med. 2018;835-401

17. Prestidge C, Romann A, Djurdjev O, Matsuda-Abedini M. Utility and cost of a renal transplant transition clinic. Pediatr Nephrol. 2012;27:295-302.

18. Harden PN, Walsh G, Bandler N, Bradley S, Lonsdale D, Taylor J, Marks SD. Bridging the gap: an integrated paediatric to adult clinical service for young adults with kidney failure. BMJ. 2012;344:e3718.

19. Schultz AT, Smaldone A. Components of interventions that improve transitions to adult care for adolescents with type 1 diabetes. J Adolesc Health. 2017;60:133-146.

20. Kelly MS, Thibadeau J, Struwe S, Ramen L, Ouyang L, Routh J. Evaluation of spina bifida transitional care practices in the United States. J Pediatr Rehabil Med. 2017;10:275-281.

21. McDonald CM, Mercuri E. Evidence-based care in Duchenne muscular dystrophy. Lancet Neurol. 2018;17:389-391.

22. Saito T, Kawai M, Kimura E, Ogata K, Takahashi T, Kobayashi M, et al. Study of Duchenne muscular dystrophy long-term survivors aged 40 years and older living in specialized institutions in Japan. Neuromuscul Disord. 2017;27:107114. 
23. https://www.nice.org.uk/guidance/qs26/chapter/Quality-statement-9Transition-from-childrens-to-adult-services (accessed August 18, 2018)

24. Appleton RE, Chadwick D, Sweeney A. Managing the teenager with epilepsy: paediatric to adult care. Seizure. 1997;6:27-30.

25. Smith PE, Myson V, Gibbon F. A teenager epilepsy clinic: observational study. Eur J Neurol. 2002;9:373-6.

26. Iyer A, Appleton R (on behalf of the British Paediatric Epilepsy Group [BPEG]). Transitional services for adolescents with epilepsy in the UK: a survey. Seizure. 2013;22:433-7.

27. http://gottransition.org/researchpolicy/index.cfm (accessed August 18, 2018).

28. Jurasek L, Ray L, Quigley D. Development and implementation of an adolescent epilepsy transition clinic. J Neurosci Nurs. 2010;42:181-9.

29. Camfield P, Camfield C, Pohlmann-Eden B. Transition from pediatric to adult epilepsy care: a difficult process marked by medical and social crisis. Epilepsy Curr. 2012;12(Suppl 3):13-21.

30. Nagra A, McGinnity PM, Davis N, Salmon AP. Implementing transition: Ready Steady Go. Arch Dis Child Educ Pract Ed. 2015;100:313-20.

31. Borlot F, Tellez-Zenteno JF, Allen A, Ali A, Sneed OC, Andrade DM. Epilepsy transition: Challenges of caring for adults with childhood-onset seizures. Epilepsia. 2014;55:1659-1666.

32. Kuchenbuch M, Chemaly N, Chiron C, Dulac O, Nabbout R. Transition and transfer from pediatric to adult health care in epilepsy: a families' survey on Dravet syndrome. Epilepsy Behav. 2013;29:161-5.

33. Mc Govern EM, Bourguignaud M, Manzato E , Mochel F, Guillonnet C , Baulac M, et al. "JUMP", an innovative trans pathology transitional care program for young adults with chronic neurological disease. Euro J Neurol. 2018; 25 suppl2:81.

34. Ried S, Specht U, Thorbecke R, Goecke K, Wohlfarth R. MOSES: An educational program for patients with epilepsy and their relatives. Epilepsia. 2001;42:76-80.

35. May TW, Pfäfflin M. The efficacy of an educational treatment program for patients with epilepsy (MOSES): results of a controlled, randomized study. Modular Service Package Epilepsy. Epilepsia. 2002;43:539-49.

36. Hagemann A, Pfäfflin M, Nussbeck FW, May TW. The efficacy of an educational program for parents of children with epilepsy (FAMOSES): 
Results of a controlled multicenter evaluation study Epilepsy Behav. 2016;64:143-151.

37. Arida RM, Scorza FA, Cavalheiro EA. Role of physical exercise as complementary treatment for epilepsy and other brain disorders. Curr Pharm Des. 2013;19:6720-5.

38. Arida RM, de Almeida AC, Cavalheiro EA, Scorza FA. Experimental and clinical findings from physical exercise as complementary therapy for epilepsy. Epilepsy Behav. 2013;2:273-8.

39. Cui W, Zack MM, Kobau R, Helmers SL. Health behaviors among people with epilepsy-Results from the 2010 National Health Interview Survey. Epilepsy Behav. 2015;44:121-6.

40. Wong J, Wirrell E. Physical activity in children/teens with epilepsy compared with that in their siblings without epilepsy. Epilepsia. 2006;47:631-9.

41. Chong J, Kudrimoti HS, Lopez DC, Labiner DM. Behavioral risk factors among Arizonans with epilepsy: Behavioral Risk Factor Surveillance System 2005/2006. Epilepsy Behav. 2010;17:511-519.

42. Capovilla G, Kaufman KR, Perucca E, Moshé SL, Arida RM. Epilepsy, seizures, physical exercise, and sports: A report from the ILAE Task Force on Sports and Epilepsy. Epilepsia. 2016;57:6-12.

43. Harden C, Tomson T, Gloss D, Buchhalter J, Cross JH, Donner E, et al. Practice guideline summary: Sudden unexpected death in epilepsy incidence rates and risk factors: Report of the Guideline Development, Dissemination, and Implementation Subcommittee of the American Academy of Neurology and the American Epilepsy Society. Neurology. 2017;88:1674-1680.

44. Berg AT, Nickels K, Wirrell EC, Geerts AT, Callenbach PM, Arts WF, et al. Mortality risks in new-onset childhood epilepsy. Pediatrics. 2013;132:124-31.

45. Sillanpää M, Shinnar S. Long-term mortality in childhood-onset epilepsy. N Engl J Med. 2010;363:2522-9.

46. Keller AE, Whitney R, Li SA, Pollanen MS, Donner EJ. Incidence of sudden unexpected death in epilepsy in children is similar to adults. Neurology. 2018;91:e107-e111.

47. Tomson T, Sveinsson O, Carlsson S, Andersson T. Evolution over time of SUDEP incidence: A nationwide population-based cohort study. Epilepsia. 2018;598;e120-e124.

48. Lin JJ, Mula M, Hermann BP. Uncovering the neurobehavioural comorbidities of epilepsy over the lifespan. Lancet. 2012.29;380:1180-92. 
49. Reilly C, Atkinson P, Das KB, Chin RF, Aylett SE, Burch V, et al. Neurobehavioral comorbidities in children with active epilepsy: a populationbased study. Pediatrics. 2014;133:e1586-93.

50. Verrotti A, Cicconetti A, Scorrano B, Berardis D, Cotellessa C, Chiarelli F, Ferro FM. Epilepsy and suicide: pathogenesis, risk factors, and prevention. Neuropsychiatric Disease and Treatment. 2008:4 365-370.

51. Sanders RA. Adolescent psychosocial, social, and cognitive development. Pediatr Rev. 2013;34:354-8.

52. Finer LB, Zolna MR. Declines in Unintended Pregnancy in the United States, 2008-2011. N Engl J Med. 2016;374:843-52.

53. Plioplys S. Depression in children and adolescents with epilepsy. Epilepsy Behav. 2003;4 Suppl 3:S39-45.

54. Williams AE, Giust JM, Kronenberger WG, Dunn DW. Epilepsy and attention-deficit hyperactivity disorder: links, risks, and challenges. Neuropsychiatr Dis Treat. 2016;12:287-96.

55. Reilly C, Agnew R, Neville BG. Depression and anxiety in childhood epilepsy: a review. Seizure. 2011;20:589-97.

56. Gray KM, Piccinin A, Keating CM, Taffe J, Parmenter TR, Hofer S, et al. Outcomes in young adulthood: are we achieving community participation and inclusion? J Intellect Disabil Res. 2014;58:734-45.

57. Braddock D, Emerson E, Felce D, Stancliffe RJ. Living circumstances of children and adults with mental retardation or developmental disabilities in the United States, Canada, England and Wales, and Australia. Ment Retard Dev Disabil Res Rev. 2001;7:115-21.

58. Ring H, Zia A, Bateman N, Jones E, Lindeman S, Himlok K. How is epilepsy treated in people with a learning disability? A retrospective observational study of 183 individuals. Seizure. 2009;18:264-268.

59. Wagner AP, Croudace TJ, Bateman N, Pennington MW, Prince E, Redley M, et al. Clinical services for adults with an intellectual disability and epilepsy: A comparison of management alternatives. PLOS ONE. 2017;12:e0180266.

60. Devinsky O, Asato M, Camfield PR, Geller E, Kanner AM, Keller S, et al. Delivery of epilepsy care to adults with intellectual and developmental disabilities. Neurology. 2015;85:1512-21.

61. Andrade DM, Bassett AS, Bercovici E, Borlot F, Bui E, Camfield P et al. Epilepsy: Transition from pediatric to adult care. Recommendations of the Ontario epilepsy implementation task force. Epilepsia. 2017;58:1502-1517. 
62. Brown LW, Camfield P, Capers M, Cascino G, Ciccarelli M, de Gusmao CM, et al. The neurologist's role in supporting transition to adult health care: $\mathrm{A}$ consensus statement. Neurology. 2016;87:835-40. 
Table 1. Nice guidelines for generic transition programs ${ }^{15}$

Age-banded clinic

Meet adult team before transfer

Promotion of health self-efficacy

Written transition plan

Appropriate parental involvement

Key transition worker for each person

Coordinated health care team,

Holistic life skills training

Transition manager for clinical team 
Table 2. Twelve goals for the transition program at Great Ormond Street, London

Goals of Independence for youth with epilepsy and normal intelligence

\begin{tabular}{|c|c|c|}
\hline & Goal & Completed \\
\hline 1 & $\begin{array}{l}\text { Remember to take your medications as prescribed (Never stop } \\
\text { without talking to your doctor). }\end{array}$ & \\
\hline 2 & Wear identity jewellery and carry some form of an epilepsy card. & \\
\hline 3 & $\begin{array}{l}\text { Always carry buccal midazolam with you (Emergency treatment } \\
\text { is important for your safety). }\end{array}$ & \\
\hline 4 & $\begin{array}{l}\text { Take control over your own hygiene needs. This involves taking } \\
\text { showers and avoiding baths (this is case you have a seizure). }\end{array}$ & \\
\hline 5 & $\begin{array}{l}\text { Make sure that are you able to tell people how they can help you } \\
\text { when you have a seizure. }\end{array}$ & \\
\hline 6 & $\begin{array}{l}\text { Organise your medications in a drug wallet that has different } \\
\text { containers for each day of the week. }\end{array}$ & \\
\hline 7 & Keep your seizure diary up to date (Paper Diary \& App). & \\
\hline 8 & $\begin{array}{l}\text { Write down any questions for health care professionals before } \\
\text { your clinic visits. }\end{array}$ & \\
\hline 9 & $\begin{array}{l}\text { Learn what medications you are on and the doses you are } \\
\text { prescribed. (Keep a copy of your prescription if this helps you } \\
\text { remember or keep a photo of the box/bottle label on your } \\
\text { phone). }\end{array}$ & \\
\hline 10 & $\begin{array}{l}\text { Ensure you have a good supply of your epilepsy medicines and } \\
\text { start ordering your own repeat prescriptions form the GP and } \\
\text { Pharmacy. }\end{array}$ & \\
\hline 11 & $\begin{array}{l}\text { Avoid situations which may trigger your seizures. Common } \\
\text { triggers include forgetting to take epilepsy medicines, lack of } \\
\text { sleep, stress or too much alcohol. }\end{array}$ & \\
\hline 12 & $\begin{array}{l}\text { Make your own medical appointments including GP and } \\
\text { Neurologist. }\end{array}$ & \\
\hline
\end{tabular}

Goals of Independence for youth with epilepsy and ID

\begin{tabular}{|l|l|l|}
\hline & Goal & Completed \\
\hline 1 & Remember when you need to take your medicines in the day & \\
\hline 2 & Learn how much liquid or how many tablets you need to take. & \\
\hline 3 & $\begin{array}{l}\text { Help your parents put your tablets in a medicine wallet for the } \\
\text { week }\end{array}$ & \\
\hline 4 & Learn the names of your medicines & \\
\hline
\end{tabular}




\begin{tabular}{|l|l|l|}
\hline 5 & $\begin{array}{l}\text { Wear an epilepsy bracelet and carry your epilepsy identification } \\
\text { card in bag. }\end{array}$ & \\
\hline 6 & $\begin{array}{l}\text { Talk to someone when you feel sad or worried and how you feel } \\
\text { about growing up }\end{array}$ & \\
\hline 7 & Tell your friends you have seizures and what happens to you. & \\
\hline 8 & Help your parents keep your seizure diary up to date. & \\
\hline 9 & Learn what sets off your seizures & \\
\hline 10 & Take more control of yourself as your body changes & \\
\hline 11 & $\begin{array}{l}\text { Before coming to clinic write down any questions for the doctors } \\
\text { and nurses. }\end{array}$ & $\begin{array}{l}\text { Talk to your parents or carers about future life plans for you to } \\
\text { live a happy life }\end{array}$ \\
\hline 12 & \\
\hline
\end{tabular}

The content of Table 2 was largely developed by Emma Ninnis, Sarah Aylett and Sophia Varadkar 
Summary of Transition Programs

\begin{tabular}{|c|c|c|}
\hline & Personnel and program & Comments/concerns \\
\hline Edmonton, Alberta & $\begin{array}{l}\text { Pediatric and adult } \\
\text { epilepsy nurse specialists } \\
\text { meet for several visits with } \\
\text { patient and family }\end{array}$ & $\begin{array}{l}\text { No generic transition } \\
\text { program } \\
\text { Little involvement of } \\
\text { physicians } \\
\text { Telemedicine overcomes } \\
\text { some long distance travel } \\
\text { problems }\end{array}$ \\
\hline Hospital for Sick Children & $\begin{array}{l}\text { There is a single visit with } \\
\text { Pediatric and adult } \\
\text { epilepsy nurse specialists } \\
\text { Pediatric and adult social } \\
\text { workers } \\
\text { Adult Neurologist } \\
\text { Adult Genetics Fellow }\end{array}$ & $\begin{array}{l}\text { Strong generic program } \\
\text { Little direct involvement of } \\
\text { pediatric epileptologist } \\
\text { except for case summary } \\
\text { Relies on single adult } \\
\text { epileptologist }\end{array}$ \\
\hline Halifax, Nova Scotia & $\begin{array}{l}\text { There are several visits } \\
\text { with Adult nurse specialist } \\
\text { Pediatric epileptologist } \\
\text { Adult epileptologist }\end{array}$ & $\begin{array}{l}\text { No generic program } \\
\text { Discontinued when the two } \\
\text { key pediatric } \\
\text { epileptologists retired }\end{array}$ \\
\hline Goteborg, Sweden & $\begin{array}{l}\text { A conference with Adult } \\
\text { epileptologist and pediatric } \\
\text { neurologists is followed by } \\
\text { continuing care with the } \\
\text { adult epileptologist. } \\
\text { Adult nurse specialist } \\
\text { becomes involved after } \\
\text { first visit with epileptologist }\end{array}$ & $\begin{array}{l}\text { Good preparation before } \\
\text { transition/transfer visit. } \\
\text { Strong system of social } \\
\text { supports }\end{array}$ \\
\hline Great Ormond Street & $\begin{array}{l}12 \text { goals for transition are } \\
\text { reviewed one at a time in } \\
\text { sequential visits (Table 2). } \\
\text { There is a series of "teen } \\
\text { talks" with epilepsy nurse } \\
\text { specialist, There is a } \\
\text { handoff clinic with pediatric } \\
\text { and adult epileptologists } \\
\text { (usually one visit) }\end{array}$ & $\begin{array}{l}\text { Strong generic transition } \\
\text { program } \\
\text { Several subspecialty adult } \\
\text { epilepsy clinics to receive } \\
\text { patients with specific rare } \\
\text { disorders }\end{array}$ \\
\hline Liverpool UK & $\begin{array}{l}\text { Adult nurse specialist, } \\
\text { Pediatric and Adult } \\
\text { epileptologists meet with } \\
\text { patient/family for } \\
\text { several visits }\end{array}$ & $\begin{array}{l}\text { Functioning successfully } \\
\text { for }>20 \text { years but no } \\
\text { overall evaluation } \\
\text { No generic program }\end{array}$ \\
\hline Necker Hospital, Paris & $\begin{array}{l}\text { There is a good generic } \\
\text { program with support from } \\
\text { a special unit "La Suite". }\end{array}$ & $\begin{array}{l}\text { Most transfers are to a } \\
\text { single expert adult } \\
\text { epileptologist at the Pitié- }\end{array}$ \\
\hline
\end{tabular}




\begin{tabular}{|c|c|c|}
\hline & $\begin{array}{l}\text { Transfer is to a hospital } \\
\text { within the Rare Diseases } \\
\text { Network }\end{array}$ & Salpêtrière Hospital \\
\hline $\begin{array}{l}\text { Pitié-Salpêtrière Hospital, } \\
\text { Paris }\end{array}$ & $\begin{array}{l}\text { Adult hospital "Jump" } \\
\text { program provides a one } \\
\text { day, multi-disciplinary } \\
\text { assessment to decide } \\
\text { further care needs }\end{array}$ & $\begin{array}{l}\text { A unique program with } \\
\text { high level of family } \\
\text { satisfaction }\end{array}$ \\
\hline $\begin{array}{l}\text { The MOSES Program, } \\
\text { Bethel, Germany }\end{array}$ & $\begin{array}{l}\text { A comprehensive program } \\
\text { with multiple teaching } \\
\text { modules delivered by } \\
\text { trained instructors in } 14 \\
\text { one hour lessons } \\
\text { longitudinally or in 2-day } \\
\text { workshop }\end{array}$ & $\begin{array}{l}\text { Randomized clinic trial has } \\
\text { established its } \\
\text { effectiveness. } \\
\text { Physicians are not directly } \\
\text { involved. }\end{array}$ \\
\hline $\begin{array}{l}\text { School of Medicine of the } \\
\text { University of Antioquia, } \\
\text { Medellin, Colombia }\end{array}$ & $\begin{array}{l}\text { One week course on } \\
\text { transition given to medical } \\
\text { students }\end{array}$ & \\
\hline India and Egypt & $\begin{array}{l}\text { Transition programs not } \\
\text { yet developed. }\end{array}$ & $\begin{array}{l}\text { Epilepsy care may be } \\
\text { throughout life by an adult } \\
\text { neurologist. Psychiatrists } \\
\text { play a significant role in } \\
\text { adult and pediatric and } \\
\text { epilepsy care }\end{array}$ \\
\hline
\end{tabular}

